\title{
Analysis on Lexical Comparative Teaching Method in the Cultivation of Postgraduates' Humanities Critical Thinking Ability
}

\author{
Xin Liu \\ The School of Public Administration, Jilin University of Finance and Economics, Changchun, China
}

Keywords: postgraduate; humanities critical thinking; lexical comparative teaching method

\begin{abstract}
This paper puts forward the binary strategy of etymology comparative teaching method and word meaning translation comparative teaching method, so as to realize the cultivation mode of postgraduates' humanities critical thinking ability with the mutual support of classroom teaching module, extracurricular guidance module and independent practice module.

The ability of humanities critical thinking refers to the ability that is internalized to the subject itself and it cannot be stripped, and the ability of a person to look at things with his own eyes and thinks about life, society, history, nature, existence, life and other propositions with a positive attitude and rich rationality, and also the process to draw an appropriate and reasonable conclusion from accurate analysis and judgment on things by understanding and thinking about problems. [1] The cultivation of humanities critical thinking ability has been paid attention since ancient times. Book of Rites, Golden Mean stresses thoughtfulness, discernment and practicing after erudition and interrogation. The lexical comparative teaching method put forward in this paper is to promote the cultivation process of modern postgraduates' humanities critical thinking.
\end{abstract}

\section{The awakening of postgraduates' humanities critical thinking awareness by "etymology comparative teaching introduction strategy"}

The key to awaken postgraduates' humanities critical thinking awareness is to guide and help them to know the "original gene" of realistic problems and have an understanding of historic origin of realistic problems. Therefore, this paper puts forward etymology comparative teaching introduction strategy, which is to describe the original forming process and meaning of a word in Chinese and western language, introduce classroom teaching, [2] and guide students to a process of critical thinking, by the aid of etymology comparative analysis in the initial teaching of postgraduates' classroom. Taking the etymology of "education” in English and "jiaoyu” in Chinese as an example, how to introduce classroom teaching with etymology comparative method is analyzed. In class, teachers shall begin with the etymology of "educate" in English and "jiaoyu" in Chinese. In Chinese, "jiao" means to "teach knowledge and skills to someone else", which is derived from its original meaning of "zhidao" (guide) and "jiaodao" (teach). After some time, the meaning of "jiao" expands to the meaning of "shiling" (make), including "shi”, "ling”, "rang". "Yu" means to give birth to baby and foster child. It is said that "The meaning of adoption aims at leading children to be a man of virtues" in Shuo Wen Jie Zi. At present, in some dialects, "give birth to baby" is still said to "foster child". Later, "yu" derives the meaning of cultivating, disciplining, and training activities. It can be seen that the meaning of "jiaoyu" in Chinese is to let children be disciplined or trained. In this process, the hierarchical relationship of dependence between the subject and object of education is vividly shown. Based on the analysis on Chinese etymology of "jiaoyu", teachers can analyze the etymology of "educate" in English. "Educate" emerged in $15^{\text {th }}$ century, and comes from "educaten" in Middle English. "Educaten" originates from Latin "Educatus", which is the past participate of "educare". In Latin, the prefix, "e" means "out", and the root "ducatus" (ducate) means "guide". Thus, the meaning of "education" in English is "guide something out", which is to guide knowledge and wisdom hidden inside children' heart with some methods; then, as for classroom introduction, teachers shall perform concluding teaching that it can be found that "there is obvious difference in the initial understanding of education or assumption 
about human nature, which results in the fundamental difference existing in Chinese and western educational concept”. For instance, China's educational concept stresses the relation of subordination between teacher and student. The "differential pattern" by Mr. Fei Xiao Tong is already deeply rooted and solidified in teaching concept, including longitudinal, rigid and hierarchical "pattern", and horizontal, flexible and self-centered "difference”. In classroom, teachers teach knowledge with self-centeredness, and maintains this hierarchical "pattern” by "enclosed" exam. Whereas, in western countries, from the Socratic Method by Socrates in ancient Greek period, to Plato, Aristotle, to modern Comenius and Rousseau, and to modern Dewey, they all continuously create the guide educational concept, and actively apply it to educational practice, which has a profound influence on western education. [3]

Based on the cases of classroom teaching, it is not difficult to find that the application of etymology comparative teaching introduction strategy, on the one hand, can reduce the "constraint" of "authoritative" oppression and administrative "evaluation" in teaching. After all, etymology of word provide learners with more subjective "form" of basic truth as much as possible. And teachers just integrate these pieced "form" of basic truth with historical logic in a story-telling way, and teach those to students. On the other hand, it can help students to understand the origin of problems, so that when analyzing realistic problems, they can not only know what it is, also how it is, and even why it is, besides, they can form their historical logic “main line' of critical thinking faced by realistic problems and awaken their awareness of critical thinking step by step, through the way of "knowledge + historical logic".

\section{The strengthening of postgraduates' humanities critical thinking awareness by "word meaning translation comparative teaching guidance strategy"}

"The master leads the apprentice into the door, but the apprentice's skill is self-made." The "self-learning" is the main part for postgraduates. However, the premise of "self-learning" is to "enter the door" first. For postgraduates, it is the processing thinking and method of literature. Whereas, the realistic problem for postgraduates is that when they get diploma, they do not know where "the door" is, what "the door" is, and do not even know how to "enter the door". The cause is the lack of effective cohesion of extracurricular guidance module in the transition from classroom teaching module to independent paper writing module for postgraduates. The "sheep-herding" guidance for postgraduates causes that they generally learn by themselves in literature processing. Sometimes, they make efforts, but they took wrong ways. Sometimes, they "play petty tricks" to "make a shortcut", but they get half the result with twice the effort. Thus, this paper puts forward word meaning translation comparative teaching guidance strategy, with the hope to connect postgraduates' classroom teaching module with independent practical module, and to realize the "re-generation" of "teamwork" initiative literature processing, so as to improve postgraduates' literature processing ability and efficiency and provide internal force for the transition from humanities critical thinking awareness to critical thinking ability.

The introduction of the word meaning translation teaching guidance strategy, originates from the guidance of the instructor, Professor Wei Sen during the academic visit to Fudan University. In the extracurricular exchanges with Prof. Wei Sen, he has made detailed comparisons and critical thinking on the translation of the three words "regime”, "system”, "institution", and the author is inspired. Professor Wei Sen compares the two meanings of the word "regime" in Oxford Advanced Learner's English-Chinese Dictionary, with the interpretation of the "zhidu" in Modern Chinese Dictionary. According to English interpretation in Oxford Advanced Learner's English-Chinese Dictionary, the first meaning of "regime" is "method or system of government", and the second meaning is "prevailing method or system of administration". Modern Chinese Dictionary divides the "zhidu" into two meanings: first, it refers to the rules of conduct and the rules of action that everyone adheres to, that is, the small system; second, it refers to the political, economic, cultural and etc. system formed under certain historical conditions. Through comparison, Prof. Wei Sen points out that the first of meaning of "regime" is corresponding to the second meaning of "zhidu". Therefore, "regime” can be called "big system”, such as capitalist regime, feudal patriarchal system 
and so on; whereas, "system" is translated into "xitong", "tizhi" and "fangfa" in Chinese. [4] Compared with "regime” and "system", "institution” is different. Prof. Wei Sen stresses that "zhidu” in Chinese cannot fully contain the wide meaning of "institution" in English. According to Oxford English Dictionary, Prof. Wei Sen considers the "institution" in English as a dynamic logic development process of "individual usage $\rightarrow$ group custom $\rightarrow$ convention from custom $\rightarrow$ formal rules, regulations, law, charters, constitution. Thus, he adheres to translate "institution" into "zhixu" (制序). The “zhi” of “zhixu” means “jianzhi”, “zhidu”, "guizhi” and etc., and "xu” means “zhixu”(秩序). [5] Rules and order are isomorphic, and the isomorphic efficiency depends on the selection of ruling method and structure. [6] In fact, "governance" appeared early in economics, management, sociology, politics and other fields, and has formed many connection between humanities disciplines. In order to accurately and specifically master the essence of "governance", it is necessary to have a panoramic understanding of related research viewpoints in knowledge field. "Good Governance”, "New Governance” and "Humanistic Governance” are full with impact force, but all are formed on the basis of thinking and systematical analysis of "regime", "system" and "institution" for a long time in the past. Besides, they have a common matrix and carrier, that is, language institution. [7] Actually, the comparative analysis by Prof. Wei Sen of word meaning translation, not only provides thinking and method of literature processing, points out the basic point of Chinese modern economic theory development process, also creates a lexical "family" in linguistics for the connection of thinking between humanistic disciplines, which is profound.

The application of word meaning translation comparative teaching guidance strategy transforms the critical thinking awareness to thinking ability used actively by postgraduates. On the one hand, in the extracurricular guidance for postgraduates, it can guide students to think and discriminate the difference and relation between foreign literature and corresponding Chinese literature by teachers, to make clear of the difference and corresponding relation of word meaning connotation range in different language environments, especially, in the comparison of cross-discipline word translation, it can help students to find the "intersection" of humanistic disciplines, and develops the habit of literature "extraction" of "book reading (original work) + journal papers + word meaning translation comparative analysis"; on the other hand, in the process of extracurricular guidance, instructors can rely on the pre-reading of postgraduates to create a group discussion, reading report, master and doctor sharing session, and other extracurricular guidance platform, giving students the opportunity to express their critical thoughts in "speaking, lecturing, and discriminating", and providing a platform for practice and expansion for the transition from critical thinking awareness to critical thinking ability, so that they can integrate group wisdom, form multi-dimensional perspectives, grasp multiple methods, and avoid copinism of postgraduates' academic experience and cognition in literature processing, to pave the way for paper writing. Here, this paper is hoped to realize the cultivation model of postgraduates' humanities critical thinking ability with effective coordination and cooperation between classroom teaching module, extracurricular guidance module and independent practice module, with the binary strategy of "lexical comparative teaching method".

\section{Acknowledgement}

Fund Program: The $12^{\text {th }}$ Five-Year Plan program of education and science in Jilin Province, Research on the Cultivation Model of College Innovative Talents from the Perspective of Right Standard (GH150272).

\section{References}

[1] Fan Huimin. The Cultivation of Humanities Critical Thinking Ability of College Students [J]. Journal of Taiyuan Urban Vocational College, 2016, (4).

[2] Gong Qianhui. Etymology Analysis of "Reading” - Taking the Teaching Connotation of Chinese "Reading" as a Core [J]. Modern Chinese, 2016, (5).

[3] Hu Peng. Etymology Analysis of “Education” [J]. Literature Education, 2016, (9). 
[4] Wei Sen. Introduction to Economic Analysis on Social Institution [M]. Shanghai Sanlian Bookstore, 2001: 5-7.

[5] Wei Sen. The Game Theory Interpretation of Hayek's Spontaneous Institutional Formation Theory: On Schotter's Economic Theory of Social System [J]. Social Sciences in China, 2003, (6).

[6] Liu Xin. The Theoretical Research on Breaking the Institution Trap of the Universities Personnel Training in China----From Obligation Standard to Right Standard [J]. Journal of Higher Education Finance, 2015, (4).

[7] Jean-Pierre Gaudin. What is Governance? [M]. Social Sciences Academic Press, 2010: 19-20. 